\title{
Organizar la solidaridad contra la represión en Córdoba. Revisiones desde la historia reciente y las políticas de memoria
}

\author{
[Organizing solidarity against repression in Córdoba. Reviews from recent \\ history and memory policies]
}

\author{
Ana Carol Solis \\ (Universidad Nacional de Córdoba) \\ acarolsolis@yahoo.com.ar
}

\begin{abstract}
Resumen
Se propone un balance provisorio de los avances producidos respecto a los modos sociales en los que se organizó la solidaridad contra la represión en Córdoba, específicamente desde el momento poscordobazo hasta la apertura del nuevo tiempo electoral. Ello surge de una preocupación ya visitada al indagar los modos sociales de responder colectivamente al incremento represivo que acompañó el ciclo de radicalización y activación política y social. Allí, sostuvimos que las denominadas comisiones de solidaridad con los presos políticos, estudiantiles y gremiales, en sus variadas formas organizativas y composiciones, fueron antecedentes directos $y$ fundamentales para comprender la organización de la solidaridad y, en otra dictadura, la conformación del movimiento de derechos humanos, aportando a dilucidar la tradición de la lucha defensista en Córdoba (Oviedo y Solis, 2006; 2007). A más de una década de aquellas escrituras, la producción académica, y en particular historiográfica, junto a la incidencia de las políticas de memoria, han modificado la disponibilidad de información y promovido nuevos abordajes en diferentes escalas de preocupaciones similares.
\end{abstract}

Palabras claves: Organizaciones defensistas Comisiones de solidaridad - Presos políticosPoscordobazo.

\begin{abstract}
A provisional balance of the advances produced concerning how the social modes of the solidarity against repression in Córdoba were organized, specifically from the post-Cordobazo moment until the opening of the new electoral time. This arises from a concern already visited during the research about the social ways of responding collectively to the repressive increase that accompanied the cycle of radicalization and political and social activation. There we argued that the so-called solidarity committees with political, student and union prisoners, in their various organizational forms and compositions, were direct and fundamental antecedents for understanding the organization of solidarity and, in another dictatorship, the shaping of the human rights movement, contributing to elucidate the tradition of the defensive struggle in Córdoba (Oviedo \& Solis, 2006; 2007). More than a decade after those writings, academic and particularly historiographic production, together with the incidence of memory policies, have modified the availability of information and promoted new approaches at different scales of similar concerns.
\end{abstract}

Keywords: Defense organizations - Solidarity commissions - Political prisoners Poscordobazo.

Recibido: 24/09/2019

Evaluación: 25/11/2019

Aceptado: 10/12/2019

Anuario de la Escuela de Historia Virtual - Año 10 - N 16 - 2019: pp. 71-92.

ISSN: 1853-7049

http://revistas.unc.edu.ar/index.php/anuariohistoria 


\section{Organizar la solidaridad contra la represión en Córdoba. Revisiones desde la historia reciente y las políticas de memoria}

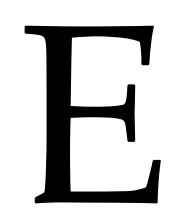

sta revisión que procura contener un balance provisorio del tema se enmarca en la Historia reciente argentina. Entiendo que dentro de este campo de preocupaciones se han realizado no sólo avances historiográficos, sino también discusiones teóricas y metodológicas que permiten recuperar las principales líneas en las que tales aportes se inscriben. En concreto, desde la historia de la represión se han producido avances fundamentales para la periodización de las acciones y modalidades represivas, para amalgamar la incidencia de las reconversiones ideológicas al amparo de los estudios sobre la Doctrina de Seguridad Nacional y las redefiniciones que, en consecuencia, operaron en la configuración de un enemigo interno. De igual manera, esta línea de investigación ha permitido la inclusión de gobiernos dictatoriales, democráticos y semidemocráticos para indagar la apelación a diferentes formas de violencia institucionalizada por parte del estado, ya sea en formas legales o ilegales, públicas o clandestinas, así como para asir las porosidades en las fronteras de cada una y la utilización conjunta de diferentes modos.

Por su parte, desde la historia de las militancias, se destacan los aportes realizados al ciclo de protesta y la reconstrucción de diferentes colectivos y redes de militancia que fueron tanto el universo de los y las represaliados como actores significativos en la organización de las acciones de denuncia, contención y asistencia a las víctimas. Dentro de ellas, la red de conflicto que me interesa se ha ligado especialmente a los avances en la historia del movimiento de derechos humanos en Argentina, considerando diferentes espacios provinciales, promoviendo debates respecto a las líneas de continuidad y ruptura en relación con estas organizaciones de solidaridad con los presos políticos y aquellas que surgieron directamente vinculadas al ejercicio del terror de estado tanto en la última dictadura como en su antesala inmediata.

Como primer acercamiento para este balance, recupero a continuación nuestro estudio de 2006 en el que postulamos que dichas organizaciones fueron antecedentes directos, aunque no iguales, de las organizaciones que posteriormente se conocieron como integrantes del movimiento de derechos humanos en Córdoba. En un segundo momento, se recuperan y analizan algunos de los aportes más significativos de la nueva etapa de producción académica, especialmente desde la disciplina histórica y las ciencias sociales. Finalmente, y en línea con las definiciones de la historia reciente que les otorgan centralidad a las políticas públicas, las acciones de memoria y otras iniciativas sociales que exceden el campo académico, se incorporan avances disponibles producidos por las agencias estatales en la coyuntura abierta desde la década del 2000.

En definitiva, proponemos retomar aquellos interrogantes que formulamos entonces para articular nuevas respuestas: ¿quiénes y cómo organizaron la solidaridad contra el avance represivo? ¿Qué lugar tuvieron los familiares de las y los represaliados en esas acciones? ¿Qué relaciones se pueden establecer entre esos modos de responder social- 
mente y las modalidades represivas principales? Para ello, se recurre a fuentes oficiales y a la creciente producción académica de la temática.

\section{Las organizaciones de solidaridad como antecedentes del $\mathrm{MDH}^{1}$}

En 2006, produjimos una primera aproximación a los modos sociales de responder colectivamente al incremento represivo que acompañó el ciclo de radicalización y activación política y social, que se materializó en un Trabajo Final de Licenciatura en Historia (Oviedo y Solis, 2006). En aquella oportunidad, y dado que la preocupación principal fue analizar la conformación del movimiento de derechos humanos en Córdoba entre 1976 y 1983, sostuvimos que las denominadas comisiones de solidaridad con los presos políticos, estudiantiles y gremiales, en sus variadas formas organizativas y composiciones, fueron antecedentes directos y fundamentales para comprender la organización de la solidaridad ante la represión de la última dictadura y la tradición de la lucha defensista en Córdoba. Es decir, sin identificar previamente su existencia ni sus relaciones con el posterior Movimiento de Derechos Humanos (en adelante, MDH), la propia indagación nos llevó a ponderar y procurar identificar y caracterizar esos modos sociales previos, de una dictadura anterior, para responder ante el avance represivo.

En efecto, situábamos como punto de inicio el escenario configurado a partir del Cordobazo, por entender, con Gordillo (1999), que desde entonces se habría dado un ciclo de protesta que transformó -junto a una serie de eventos similares en diferentes espacios del país- la protesta y movilización precedente en un ciclo de mayor conflictividad y rápida difusión, con la incorporación de nuevos sujetos activos y la progresiva conformación de un movimiento de oposición al régimen de la dictadura. ${ }^{2}$ Esa delimitación se justificaba porque pensábamos que las organizaciones de solidaridad podían haber existido previamente, dada la larga persistencia de redes de conflictos que implicarían la persecución (estatal, aunque no solamente) a la disidencia y, en consecuencia, asumíamos la organización de diferentes y situadas formas históricas de respuestas sociales a la represión, pero postulábamos al Cordobazo como un momento clave para comprender la dinámica más reciente de aquella red y sus efectos. En resumidas cuentas, hacíamos propia una lectura del Cordobazo, siguiendo a Gordillo (1999), como disparador de un proceso de difusión de las protestas y de rápida conformación de un marco activador basado en la ilegitimidad de un gobierno que buscaba erradicar "la política", en lo que, hasta entonces, eran sus canales y modalidades predominantes, lo que dio inicio a un ciclo de protesta (Oviedo y Solis, 2006). ${ }^{3}$ No es objetivo de este artículo referir ese pro-

\footnotetext{
${ }^{1}$ Se recupera específicamente el planteo general de la perspectiva y los aportes del capítulo 3 de la TFL, pero sólo hasta 1973. En la versión original se continuó hasta el escenario inmediato anterior al golpe de estado de 1976 (Oviedo y Solis, 2006). Síntesis y nuevos avances del mismo tema (Oviedo y Solis, 2007; Solis, 2014; Iturralde y Solis, 2015).

${ }^{2}$ Entendíamos que, en los sesenta, particularmente con el Onganiato, se habría configurado un ciclo de politización y movilización que, como contraparte, generó el aumento de las estrategias represivas del Estado. Acciones disruptivas y capacidad represiva se combinaron entonces, dando lugar a un período signado por la presencia de marcos movilizadores y la rápida difusión de las protestas.

${ }^{3}$ Hacia 1971 ese ciclo de protesta, parafraseando a Gordillo (2001b, p. 20), encarnado en acciones como el Viborazo o segundo Cordobazo y el plenario de Gremios Combativos, derivó en la conformación de un movimiento de oposición al régimen. Desde entonces, una nueva coyuntura política comenzó a delinearse cuando, ante el fracaso de la estrategia del Gran Acuerdo Nacional (GAN), que combinó negociación y represión, el gobierno de la Revolución Argentina aceptó la realización de elecciones.
}

Anuario de la Escuela de Historia Virtual - Año 10 - Nº 16 - 2019: pp. 71-92. ISSN: 1853-7049 
ceso, sus actores y modos de acción; sí me interesa destacar que, ante el ciclo de protesta y, en particular, tras el Gran Acuerdo Nacional (GAN), por su fracaso en cobijar herederos del régimen, la principal estrategia del gobierno, a medida que la protesta aumentaba, consistió en el uso de la negociación y, principalmente, de la represión. ${ }^{4}$ En lo que sigue, abordaremos lo que identificamos como una red de conflicto que progresivamente se convirtió en prioritaria a partir de la demanda de "libertad a los presos".

\section{“Libertad a los compañeros". Las organizaciones de solidaridad}

Encontramos persistencias en la persecución y represión de los diferentes disidentes configurados en el país, por los menos en el siglo XX, e identificamos también que la creación de espacios de resistencia y, en particular, de organismos de defensa y solidaridad para con los perseguidos y encarcelados reconocía numerosos antecedentes. Además de su antigüedad, conviene destacar que muy variados fueron también los formatos que tales organismos han tomado. Sin embargo, más allá de su heterogeneidad, la presencia de familiares directos de los afectados por la represión y de abogados comprometidos políticamente con la causa de sus defendidos eran elementos recurrentes que se mantendrán en el tiempo. Incluso, la tendencia a constituir espacios desde el pluralismo ideológico tampoco fue totalmente nueva. Con relación al tipo de organizaciones en la tradición defensista, remitíamos a dos casos de signo distinto: por un lado, y dentro de las organizaciones que han tenido mayor duración, la Liga Argentina por los Derechos del Hombre (LADH) existía en el país desde la década de 1930. ${ }^{5}$ Por otro, y focalizando la acción de los profesionales del derecho, recuperábamos el aporte de Mauricio Chama (2000) sobre la politización y radicalización de los grupos de abogados vinculados al peronismo de izquierda, señalando las estrategias y los espacios de acción predominantemente utilizados a medida que la represión comenzó a generalizarse.

Una característica de este nuevo ciclo defensista que observamos desde fines de los años sesenta fue la actuación -individual o conjunta- de algunas de estas agrupaciones previas, pero sobre todo el involucramiento cada vez mayor y más directo de las organizaciones sindicales y de los abogados a ellas ligadas. Esto, junto a la mayor presencia de los familiares directos que comenzaron a organizarse, fue caracterizando al espacio articulador de las tareas pro libertad de los detenidos hacia fines de la década del sesenta y principio de la década siguiente. A ello se agregó la irrupción de las "modernas" organizaciones armadas que en 1970 habían logrado visibilidad pública por la espectacularidad de sus acciones y su capacidad operativa. Por lo tanto, la persecución y encarcelamiento de dirigentes y/o activistas sindicales, políticos o estudiantiles y -cada vez más- de miembros de las organizaciones armadas fue la consecuencia del aumento

\footnotetext{
${ }^{4}$ Esta línea de acción no puede desvincularse analíticamente de otro proceso: aquél por el cual se iban generando adhesiones en torno a la necesidad de reprimir estas manifestaciones "disociadoras", posición ideológicamente sustentada en la incorporación del discurso de la Doctrina de Seguridad Nacional y en la formación contrainsurgente de militares argentinos.

${ }^{5}$ Por su rol histórico en este ámbito y su activa participación en la década de 1970, la LADH está reconocida como uno de los ocho organismos clásicos de derechos humanos. Fundada en 1937, la Liga se convirtió en refugio para perseguidos políticos y espacio de contención para los familiares de detenidos. Su acción continuó, en las décadas siguientes, asistiendo jurídicamente a los detenidos y tomando posición frente a acontecimientos claves del ámbito nacional e internacional. Por ello, en opinión del autor y hasta 1975, este organismo fue blanco predilecto de la represión por ser "punto obligado de referencia para la defensa de los derechos humanos"' (Veiga, 1985, pp. 18-21).
}

Anuario de la Escuela de Historia Virtual - Año 10 - N 16 - 2019: pp. 71-92. ISSN: 1853-7049 
de las acciones de protesta y de las acciones armadas; máxime cuando el ciclo de protesta inaugurado tras el Cordobazo devino, como señaláramos, en el surgimiento de un movimiento de oposición política basado en un profundo y generalizado cuestionamiento a la continuidad del régimen autoritario (Gordillo, 2001c, pp. 29, 30).

Antes de continuar con las estrategias y espacios de resistencia a la represión, conviene mencionar que no se trató únicamente de un cambio cuantitativo. Decíamos entonces que, para Duhalde (1999, p. 40), se introdujeron también novedades en las modalidades represivas. En primer lugar, el autor advertía en su trabajo clásico que tempranamente, desde 1970, se recurrió al secuestro con fines de desaparición, mediada por la tortura como método para extraer información. Y, si bien estos casos resultaron excepcionales en el conjunto de los modos más difundidos, su analogía con procesos posteriores no deja de sorprendernos. Por otro lado, y con relación a los métodos más comunes, afirmaba que las masivas detenciones sin juicio a disposición del Poder Ejecutivo Nacional, las torturas sistemáticas, el régimen inhumano de prisión, la sustracción de los detenidos a sus jueces naturales, las modificaciones del código penal admitiendo el principio de analogía y creando figuras ambiguas como componentes de este giro represivo.

En respuesta a esto, en aquella investigación postulamos que la dinámica pasó a caracterizarse por la conformación de espacios de solidaridad con los presos "políticos, estudiantiles y gremiales" -según la denominación contemporánea. Entre ellos existió una gran variedad, con diferentes grados de inscripción institucional. Más allá de las divergencias en formato, origen y composición, tenían en común la demanda generalizada de liberación de los detenidos y las acciones de denuncia sobre las condiciones de encierro y los traslados "disciplinadores". Por otra parte, cabe mencionar que, para muchos, el surgimiento de estos espacios de solidaridad fue crucial por cuanto se constituyeron en ámbitos de militancia y, en ocasiones, en el paso previo a la incorporación en otras organizaciones políticas. Volviendo a los espacios, a los que genéricamente se ha denominado "comisiones de presos" y que reconocíamos como antecedente de los posteriores organismos de derechos humanos, ellos representaron diferentes modelos, desde la noción de estructuras movilizadoras. Así, por ejemplo, encontramos las comisiones de solidaridad que, en su mayoría, tenían una fuerte inscripción institucional y, como en el caso de la CGT Regional Córdoba, se formaron dentro de una institución huésped. Otras, más ligadas al fenómeno de la nueva izquierda, planteaban discursivamente unir la lucha de los presos con la lucha contra el régimen, como la Organización de Solidaridad con los Presos Políticos, Estudiantiles y Gremiales (en adelante, O.S.P.P.E.G.); que algunos sostienen estuvo ligada al clasismo.

Los grupos de los familiares de detenidos podían actuar dentro de estas mismas comisiones o en organizaciones propias. En la memoria de los protagonistas que entrevistamos, la designación genérica de "comisiones de familiares", para estas primeras modalidades de acción, pareciera remitir, en ocasiones, a estos espacios plurales en los que familiares y militantes políticos y gremiales convergían en la acción de defensa y solidaridad con los detenidos y en las que resulta difícil reconstruir las fronteras de cada espacio; y en otras, a las iniciativas exclusivas de familiares. Sobre estas afinidades, una entrevistada sostiene: "Nuestro lugar era la sede de la CGT en la calle Gral. Paz con Tosco y López, porque ellos estaban defendiendo también a sus propios presos." ${ }^{\prime 6}$

\footnotetext{
${ }^{6}$ Entrevista a Nelly, Córdoba, noviembre de 2005 (Oviedo y Solis, 2006). Todas las citas referidas a la entrevista de Nelly están incluidas en el capítulo 3. La entrevista fue realizada por S. Oviedo.
}

Anuario de la Escuela de Historia Virtual - Año 10 - N 16 - 2019: pp. 71-92. ISSN: 1853-7049 
Con relación a la conformación de espacios nuevos, la señora Nelly refería respecto a sus memorias del origen de Co.Fa.PPEG en Córdoba y el perfil de sus integrantes: ${ }^{7}$

“[...] a fin de ese primer año [1970] ocurren dos hechos notorios en Córdoba: cae un grupo de chicos de familias muy notorias de la sociedad denominados Montoneros, quisieron tomar La Calera, el arsenal de la policía, yo aún no entendía cómo se arriesgaban. Al mes cae un hijo mío, en noviembre de 1970. Me acuerdo bien, vuelvo a mi casa de Argüello y sufrimos un allanamiento, mi hijo había querido tomar las armas de una armería sin violencia, ellos planteaban la revolución popular y que se adhirieran y pedían para eso las armas. El armero llamó a la policía y por eso llevan preso a mi hijo Sebastián y a seis más; bueno, fuimos con las madres, algunas de ellas eran mis amigas, y con las cuatro que se agregan iniciamos la Unión de padres para defender a los presos. Nos entregaron la ropa ensangrentada, los torturaron. Las madres hicimos un juramento: defender a nuestros hijos como presos políticos, que seguían un ideal de cambio social, frente a la cantidad de golpes que se sucedían. Veíamos con horror ese militarismo, en los círculos que frecuentábamos nosotros, católicos de alto vuelo, decíamos haga patria y mate a un milico, pero sólo de la boca para afuera los mayores sólo lo decíamos, los jóvenes fueron a la acción, fue una reacción seria contra eso. Con ese grupo original de madres organizamos la Co.Fa.PPEG, de Córdoba, estaba la señora Irma de Fierro secretaria, Blanquita Lozada... me olvido los apellidos; el señor Ceballos, tesorero, la señora Teresita Grafignia de Conte Grande -su esposo era médico, cayó preso con Montoneros- la señora Piotti de Salguero; de ellas no me olvido nunca. Los pilares eran siete primero y cuatro más eran del E.R.P. [Ejército Revolucionario del Pueblo] y de Montoneros y algunos también de las agrupaciones estudiantiles... hacían actos, panfleteaban, asambleas públicas, en los sindicatos". ${ }^{8}$

La fuerte impronta militante de este nucleamiento puede colegirse también de publicaciones de épocas, ayudando a contextualizar sus prácticas. En referencia a los integrantes y objetivos de Co.Fa.PPEG, el entrevistado responde:

[...] es un nucleamiento de familiares de presos políticos, estudiantiles o gremiales del régimen. Nuestro objetivo, como no puede dudarse, dado nuestro carácter de familiares que estamos orgullosos de los seres que están detenidos, no ha sido otro que luchar para obtener la libertad de los mismos. ${ }^{9}$

Si el anterior reúne originalmente a familiares, la Comisión de Solidaridad constituida en el seno de la CGT Regional Córdoba tenía un perfil un tanto diferente, por constituir ya previamente una organización que contenía la identidad de los represaliados, aunque incluyese a otros no propios. Recordemos que, como corolario del proceso de radicalización y de irrupción de las bases, un nuevo escenario en el ámbito sindical quedó configurado en abril de 1971 cuando los sectores combativos lograron quedarse con la con-

\footnotetext{
${ }^{7}$ La sigla corresponde a Comisión de Familiares de Presos Políticos, Estudiantiles y Gremiales. Esta organización funcionó desde 1970, en diferentes lugares del país, hasta que finalmente fue prohibida después del Golpe de Estado del 24 de marzo. Como surge del relato de Nelly, la misma estaría conformada principalmente por familiares de detenidos vinculados a organizaciones armadas. Al menos, en Córdoba, de sus integrantes iniciales, la mayoría eran madres y padres de miembros de ERP y Montoneros.

8 Entrevista a Nelly, Córdoba, noviembre de 2005.

9 “Entrevista con COFAPPEG”, Posición, año I, 5, Suplemento 2. La situación de los presos políticos. Córdoba, mayo de 1973, p. 19.
}

Anuario de la Escuela de Historia Virtual - Año 10 - Nº 16 - 2019: pp. 71-92. ISSN: 1853-7049 
ducción de la CGT local. Ello ocurrió con Atilio López -del peronismo legalista- en el cargo de secretario general, acompañándolo Agustín Tosco -sector independientecomo secretario adjunto (Gordillo, 2001c, pp. 37-39).

La central se convirtió en un referente clave del proceso de movilización, sobre todo desde la cuestión que nos ocupa. En este ámbito, se creó una Comisión de Solidaridad que inició una serie de recitales populares a beneficio de los presos políticos, estudiantiles y gremiales y de los trabajadores de FIAT. También utilizaron las comunicaciones formales al Ministerio del Interior para pedir la liberación de los presos y el levantamiento de las órdenes de captura a los dirigentes. ${ }^{10}$ La demanda de libertad tanto para dirigentes sindicales como para miembros de las organizaciones armadas se incluyó en la parte resolutoria del Plenario de Gremios Combativos. Dentro de las acciones de solidaridad, hubo actividades conjuntas con los familiares de los presos, con ayuda material y moral y, además, intentos de nacionalizar la demanda de libertad, mediante una conferencia de prensa en Buenos Aires. ${ }^{11}$ Se advierte también la participación solidaria de otros grupos activados como los sectores religiosos ligados a la opción de Medellín y el activo rol de la Agrupación de Abogados de Córdoba, quienes realizaron un paro con cierre de estudios jurídicos y acto frente al Colegio de Abogados. El espectro era bastante heterogéneo, pues, como mencionáramos, diferentes grupos se habían conformado para la denuncia y defensa de los detenidos. Así, en el trabajo citado, encontramos un nuevo agrupamiento: "Movimiento Nacional de Solidaridad con los presos políticos". El mismo promovió una huelga de hambre a fines de 1972 (Gordillo, 2001a, pp. 51-57). La misma acción fue llevada a cabo en Córdoba en la sede de la CGT con las siguientes adhesiones:

“[...] COFAPPEG, SMATA, OSPPEG, P.C.R., paritarios de IME, Sindicato de Prensa de Córdoba, Agrupación de Abogados, Movimiento Bancario de Bases, SITRAC-SITRAM, CEFyL (Filosofía), Curas del Tercer Mundo, Luz y Fuerza, Movimiento Nacional de Solidaridad, Sindicato de Obras Sanitarias, $B^{\circ}$ Nicolás Avellaneda, Vanguardia Comunista, TUPAC, Franja Morada, Juventud Peronista, Partido Justicialista, Grupo de octubre (Buenos Aires), Movimiento Popular de Córdoba, Centro de estudiantes de Arquitectura (MUA), M.N.R. (...) se hallaba anoche presente (...) Ricardo Obregón Cano y por el Grupo Octubre, que es una agrupación de teatro, el actor Norman Briski". ${ }^{12}$

Y aunque las redes de solidaridad eran cada vez más amplias, también existieron tensiones entre los grupos activados que, motivadas por las posiciones asumidas frente a cuestiones específicas de cada ámbito -como, por ejemplo, las diferencias entre el clasismo y la conducción de la CGT de Tosco y López- se reflejaron igualmente en la adhesión y preferencia por distintos espacios de solidaridad. Nuevamente, un ejemplo del clasismo ilumina este punto: Gregorio Flores, desde la prisión en Rawson escribía a fines de 1971, al comentar sus diferencias respecto a la CGT:

\footnotetext{
${ }^{10}$ El avance de la represión para quienes no acordaban con la propuesta del GAN significó, por ejemplo, la prisión del propio Agustín Tosco, recluido en el penal del Sur.

${ }^{11}$ Asistieron distinguidos abogados en la defensa de los presos políticos como Solari Yrigoyen y otros aliados influyentes. Se sumaron agrupaciones políticas, estudiantiles y gremiales. La lista completa en Gordillo, (2001a, p. 55).

${ }^{12}$ La Voz del Interior (LVI), Córdoba, 31/12/1972, p. 5.
}

Anuario de la Escuela de Historia Virtual - Año 10 - N 16 - 2019: pp. 71-92. ISSN: 1853-7049 
“En esta breve charla le recalqué que, si la CGT tenía sinceras intenciones de colaborar con los presos políticos, debía hacerlo a través del O.S.P.P.E.G., que fue el primer organismo -en Córdoba- que tuvo una clara definición política y una decidida identificación con los presos populares. Uds. nada me dicen de las diferencias o escisiones producidas en O.S.P.P.E.G., pero, de cualquier manera, a pesar de que existan varias versiones, la postura del O.S.P.P.E.G. me parece la más correcta, y pienso que ahí estarán Uds. en la medida de sus posibilidades" (Flores, 2004, p. 235).

Con respecto a la Organización de Solidaridad con los Presos Políticos, Estudiantiles y Gremiales, se habría conformado hacia 1970, con una clara orientación política. Cuando iniciamos esta investigación, el Partido de la Liberación, que se reivindica continuador de la organización setentista Vanguardia Comunista, refería que tal agrupación tuvo un rol protagónico en la fundación de la O.S.P.P.E.G. El artículo sostiene además que las diferencias en la política de derechos humanos habrían sido, principalmente, con la LADH respecto a si unir o no la lucha por los derechos humanos con la lucha "contra el régimen" (Soto, 2004).

Por sobre las diferencias y tensiones entre organizaciones de defensa y solidaridad, las tareas comunes emprendidas combinaban la asistencia jurídica, denuncia pública y, principalmente, organización de las visitas de familiares a los penales. Para ello, las actividades solidarias realizadas con el objeto de lograr el financiamiento de los viajes se volvieron centrales contando con amplias adhesiones, sobre todo, cuando la política del régimen echó mano de los traslados como medida de disciplinamiento. ${ }^{13}$ La temática de los traslados de detenidos debe asociarse a la función desempeñada por el penal de Rawson, por ejemplo. Dicha cárcel representaba, en el imaginario de los contemporáneos, la condensación de la política represiva de la Revolución Argentina por ser, al mismo tiempo, la imagen de la lejanía forzada por el traslado -en donde sus prisioneros llegaban a conformarse como una comunidad de destino- ${ }^{14}$ y la anticipación de lo que vendría, al generalizarse la aplicación de la ley de fuga. ${ }^{15}$ En el primer sentido aludido, una familiar recuerda:

“Luego los llevan a Rawson, esa cárcel era terrible, era de condenados y nuestros hijos no tenían juicio; fue como una expatriación, llevarlos lejos, confinarlos para que

\footnotetext{
${ }^{13}$ Decía una entrevistada al respecto: “Debíamos asistir a nuestros presos que eran trasladados de un lugar a otro, Onganía manejaba a los jueces federales como muñecos, pasaban de una jurisdicción a otra, por ejemplo, los llevaron al Chaco, allá fuimos todos los padres, teníamos como un fondo para viajar y asistir a nuestros chicos." Entrevista a Nelly, Córdoba, noviembre de 2005.

${ }^{14}$ La expresión "comunidad de destino" es tomada por Scott (2004 [2000], p. 165) para situar a grupos de trabajadores que tienen una fuerte tendencia a compartir una clara imagen antagónica de sus patrones y a actuar solidariamente entre ellos. En este caso, el uso de esta categoría se vuelve pertinente al considerar las condiciones de cautiverio prolongado que tuvieron muchos detenidos y su estancia en diferentes cárceles del país. Al respecto, el dirigente clasista Gregorio Flores recuerda: “Antes de estar detenidos nosotros, el Sitrac-Sitram integraba la comisión de solidaridad con los presos políticos a donde concurríamos con mucha frecuencia. En esas visitas a la cárcel de encausados conocí a muchos presos que después serían mis compañeros en la cárcel de Rawson". La cursiva es nuestra (Flores, 2004, p. 192).

${ }^{15}$ Con esta expresión se alude a una modalidad represiva que consiste en el asesinato de presos que previamente han sido sacados de las cárceles y ejecutados pretendiendo falsos intentos de fuga; aplicada generalmente a casos de presos "legales", o sea reconocidos como tales.
}

Anuario de la Escuela de Historia Virtual - Año 10 - Nº 16 - 2019: pp. 71-92. ISSN: 1853-7049 
no los viéramos; pero lo mismo fletábamos colectivos y los visitábamos, allí, en Santa Fe, Caseros, Chaco, el buque cárcel, ya eran como 1000, todo antes de la Amnistía".16

En un segundo sentido, debe recordarse que el 22 de agosto de 1972 murieron fusilados dieciséis prisioneros y tres resultaron gravemente heridos. Todos ellos se habían rendido entregando sus armas, tras el fracaso de un intento de fuga en el aeropuerto de Trelew. Este episodio, negado por sus responsables, se ha popularizado como la Masacre de Trelew y representa un caso paradigmático por contener varios elementos de lo que sería luego una modalidad típica del terrorismo estatal. ${ }^{17}$ Descorrer el velo sobre este episodio se convirtió en una de las tareas asumidas por los grupos movilizados, haciendo aflorar aquello que el discurso oficial ocultaba tras la deformación de los acontecimientos.

Por último, agregábamos que el recorrido por los antecedentes mediatos de las formas de represión y las estrategias de resistencia con un foco en la conformación de comisiones proliberación de los detenidos no sería representativo si no se incluyera la acción específica de los profesionales del derecho. En Córdoba, en esta etapa, existió una fuerte vinculación entre los gremios, las organizaciones políticas, los abogados y los familiares de los detenidos. ${ }^{18}$ La combinación de una estrategia defensista de larga data con un fuerte compromiso político por parte de muchos profesionales del derecho se manifestó en la aparición de nucleamientos de abogados en los primeros años de la década del '70. Alfredo Curutchet representa una figura emblemática de este proceso de radicalización de grupos profesionales, convirtiéndose también ellos en blancos de la represión. ${ }^{19}$

Ahora bien, el objetivo es llevar a cabo un ejercicio de balance mediante un recorrido por nuevos aportes que entraman, complejizan y tensionan lo que entonces postulamos sobre la defensa y solidaridad con los presos políticos.

\section{Los aportes desde la historia reciente}

En la conjunción entre la historia de la represión y la historia de las militancias se cuentan las principales contribuciones para enmarcar y entramar la organización de la solidaridad con los detenidos. Concretamente, desde la primera, avances significativos se han incorporado con la tesis doctoral de Ariel Eidelman (2010) que historiza el desarrollo de los aparatos represivos en la Revolución Argentina. Concentra su atención en las bases doctrinarias y la estructuración represiva desde 1966, identificando un proceso de generalización de desapariciones y aumento de la acción represiva paraestatal desde 1970 en adelante. Asimismo, analiza la instrumentación de procesos punitivos específicos, tales como el fuero antisubversivo y el denominado “Camarón” entre 1971 y 1973, que fun-

\footnotetext{
16 Entrevista a Nelly, Córdoba, noviembre de 2005.

${ }^{17}$ Los componentes que anticipan tal metodología son: política genocida, pedagogía del terror, no asunción de la autoría del hecho criminal, pacto de sangre y aplicación de la ley de fugas (Duhalde, 1999, p.41).

${ }^{18}$ Gordillo (2001c) conceptualiza el trabajo de los abogados desde la categoría de aliados influyentes del proceso de movilización social y política, destacando su activa intervención: “[...] los abogados que no solo asesoraron a la nueva dirigencia, sino que iniciaron sistemáticas campañas de reclamos por la liberación de los presos políticos y sindicales." (Gordillo, 2001c, p. 31).

${ }^{19}$ Gregorio Flores recuerda: “Numerosos compañeros fueron enviados a la cárcel y junto con ellos nuestros abogados del sindicato, el Cuqui Curutchet y Martín Federico." (Flores, 2004, p. 197). Al respecto debemos recordar que Curutchet fue asesinado por la "Triple A" el 10 de septiembre de 1974 (Servetto, 1998, p. 138).
} 
cionó como un tribunal especial. El autor dedica incluso atención a la conformación de subjetividades y disposiciones a la acción represiva, al abordar en revistas policiales la construcción identitaria de la policía federal y de determinadas representaciones sobre la violencia política. Finalmente, aborda de modo particular el mundo de la prisión política y las transformaciones operadas en los penales, su progresiva militarización y las respuestas sociales que generó, tema sobre el que volveremos.

Sobre los efectos que produjo el aumento y cambio de la represión en los sesenta y setenta de Argentina, otra contribución destacada es la tesis doctoral de Débora D'Antonio (2016), quien focaliza la prisión política dentro de la trama represiva. Su clave es trabajar la prisión política en los años setenta desde una mirada que hace converger historia, género y política. De este modo, dedica dos capítulos a historizar la represión y, en particular, el lugar y las transformaciones operadas en ella al interrogarse por el sentido preciso de la prisión política en esos años, sus particularidades y diferencias respecto a otras formas y modalidades represivas y el rol del servicio penitenciario dentro del sistema represivo. Pero, además, investiga qué significó y cómo se articuló la prisión política para mujeres y varones, reconstruyendo las condiciones del encierro diferenciadas, los procesos de desubjetivación y la sexuación del castigo a la que ambos fueron sometidos. Si bien la periodización de su tesis es entre 1974 y 1983, aporta claves de lectura para una dimensión temporal más amplia al inscribir a la cárcel dentro del sistema represivo y de control social que atraviesa ambas dictaduras, buscando discutir los estudios que tratan a la última dictadura en términos de excepcionalidad por los centros clandestinos y la desaparición. En efecto, con la autodenominada Revolución Argentina se habría dado un proceso de modernización y especialización muy ligados a las reconversiones promovidas por la doctrina de seguridad (al amparo de la DSN) ${ }^{20}$, que modificó la infraestructura y adecuó reglamentaciones, a fin de contener y diferenciar la creciente población del encierro político y a establecer en ella gradaciones de peligrosidad, en un contexto de una mayor militarización de la seguridad e interpenetración entre las fuerzas militares y el espacio carcelario ${ }^{21}$ (D'Antonio, 2016, pp. 70-86). Con el aumento de presas y presos políticos hubo también numerosas fugas, entre las que se mencionan la del Buen Pastor en junio de 1971 en Córdoba y la emblemática de Trelew, lo que abonó la concentración en penales de mayor seguridad. En síntesis, ambos trabajos ayudan a situar la centralidad de la prisión política (aunque recayese sobre diferentes colectivos activados) en el dispositivo represivo y disciplinador del conflicto y la amenaza insurgente durante la Revolución Argentina, mostrando conexiones entre las dos dictaduras.

Otra línea de indagación potente, y complementaria de la anterior, se vincula a los cambios regionales y nacionales promovidos por el paradigma de la seguridad nacional al amparo de la Doctrina de Seguridad Nacional y su configuración de un enemigo interno, analizando su incidencia en las transformaciones institucionales, y en la legitimación, organización y efectos de la represión. En esa perspectiva, resulta insoslayable el trabajo de Esteban Pontoriero (2015), que historiza ese proceso, volviendo asequible las

\footnotetext{
${ }^{20}$ Tanto Eidelman como D'Antonio desarrollan la incidencia de la DSN en Argentina, especificando las transformaciones en la formación contrainsurgente, la vinculación internacional y regional y su incidencia en la organización nacional del sistema represivo.

${ }^{21}$ Se habría producido una creciente militarización de las fuerzas de seguridad y policiales y, a su vez, una creciente participación de los militares en tareas policiales, una policialización de las fuerzas armadas podríamos decir. A ello se sumó que, a comienzos de 1973, bajo el gobierno de Lanusse, el Servicio Penitenciario Federal que tendrá a su cargo (D'Antonio, 2016).
}

Anuario de la Escuela de Historia Virtual - Año 10 - N 16 - 2019: pp. 71-92. ISSN: 1853-7049 
múltiples incidencias y reconfiguraciones que produjo el cambio en la concepción del enemigo y las responsabilidades estatales en su combate. Igualmente, Franco e Iglesias (2015) adicionaron una perspectiva comparativa regional de los institutos del estado de excepción en diferentes experiencias conosureñas.

Ahora bien, considerando específicamente las respuestas sociales al avance de pautas represivas y disciplinadoras del conflicto y la acción insurgente, me voy a detener en las ampliaciones y resignificaciones que se operaron en relación a nuestro objeto de interés, esto es, la solidaridad (y la acción defensista) conformada desde diferentes organizaciones viejas y nuevas en el escenario postcordobazo. En efecto, se han producido contribuciones significativas en prácticamente la mayoría de las cuestiones que habíamos apuntado en nuestro trabajo de 2006. Por un lado, respecto de la acción de los abogados defensistas, los trabajos de Mauricio Chama, así como otras iniciativas institucionales, han densificado y particularizado el lugar de los abogados comprometidos en la defensa de las y los presos políticos frente al avance represivo. En efecto, Chama (2016) brinda una contribución global para pensar en el activismo de defensa y solidaridad con los presos políticos, al cartografiar los actores y sus tramas y al proponer un enfoque desde los procesos de movilización y de construcción de causas públicas, que permite iluminar cuestiones menos trabajadas. En su argumento central postula: "el marco que permite comprender este proceso de articulación y convergencia entre estos actores fue la puesta en marcha de una serie de acciones comunes, así como también un modo compartido de definir al preso político, situándolo dentro de un campo de relaciones más amplias. [...] el trabajo también aborda el proceso de construcción de la denuncia pública, incluyendo las principales categorías mediante las cuales definieron la situación de los presos políticos como un problema social en la arena pública" (Chama, 2016, p. 4). El autor reflexiona así sobre el proceso de creación de la causa de los presos políticos en la Argentina de los setenta, aludiendo a las oportunidades, las estructuras movilizadoras, las redes locales y trasnacionales y los procesos de enmarcamiento; una causa que fue un componente significativo del frente antirrepresivo y antidictatorial, lo que permite valorar así su incidencia en las derivas sobre el régimen y su crisis. ${ }^{22}$ Dentro de los nucleamientos, Chama distingue tres vertientes, según sus integrantes, áreas de acción y vínculos con otras organizaciones y partidos. Por un lado, los grupos conformados según expertise profesional, es decir, abogados que defendieron a los presos políticos. Destaco sus aportes sobre la Asociación Gremial de Abogados, surgida en 1971 que habría tenido réplicas en La Plata, Rosario, Córdoba, Entre Ríos, Mar del Plata. Estos grupos y redes accionaban legalmente y denunciaban la represión. Por otro, las asociaciones basadas en vínculos sanguíneo y familiar con las y los presos políticos. En Córdoba: "Este fue el caso de la COFAPEG, creada primero en Córdoba 1971 y un año después en la Capital Federal, por iniciativa de Susana Gaggero, esposa del dirigente del PRT-ERP Luis Pujals, desaparecido en septiembre de 1971" (Chama, 2016, p. 7), lo que replicaba experiencias previas como COFADE, que fuera de familiares de presos CONINTES. Por último, los nuclea-

\footnotetext{
${ }^{22} \mathrm{El}$ autor construye un mapa de las organizaciones de comienzos de los años setenta en el que incluye a las siguientes: “[...] la Asociación Gremial de Abogados (AGA), el Foro de Buenos Aires por la Vigencia de los Derechos Humanos (Foro), la Comisión de Familiares de Presos Políticos, Estudiantiles y Gremiales (COFAPPEG), la Comisión Nacional contra la Represión y la Tortura (CNRyT), la Organización de Solidaridad con los Presos Políticos, Estudiantiles y Gremiales (OSPPEG), la Comisión Peronista de Ayuda a los Presos Políticos (COPAPP), la Coordinadora de Lucha por la Libertad de los Presos Políticos" (Chama, 2016, p. 5).
} 
mientos formados por notables, donde se incluirían redes trasnacionales, con intelectuales, artistas y referentes comprometidos -como el Foro de Buenos Aires por la Vigencia de los Derechos Humanos-. Por su parte, el Movimiento Nacional contra la Tortura y la Represión, creado en 1971, sería una organización intermedia entre las segundas y las terceras, pues reunía afectados directos y redes solidarias de denuncia. Por último, menciona otras comisiones y coordinadoras, en general ad hoc y más efímeras, donde integra a la OSPPEG, que, como vimos, tuvo participación en Córdoba. Y confirma, siguiendo a Celentano (2014), que ésta surgió en el poscordobazo ligada a Vanguardia Comunista y muy cercana en su actuación a los sectores clasistas. Otra comisión relevante fue la "Comisión de Solidaridad con los Presos Políticos y Sociales de Rawson", formada por la comunidad cercana al penal.

Nuevamente, retomamos a Eidelman (2010) para referir a las comisiones en la etapa poscordobazo. El autor reconoce como antecedentes directos del $\mathrm{MDH}$ a esa trama de denuncia y solidaridad con los presos políticos, íntimamente vinculada a los cambios cuantitativos y cualitativos de la represión. Desde 1966, historiza el accionar de espacios existentes como LADH, grupos de abogados, pero también de la CGTA que actuará de referente en la denuncia de la represión. Con relación a los nuevos nucleamientos, destaca la acción de al menos tres grupos de organizaciones: las que integran principalmente el compromiso político de los abogados; las que integran a familiares (algunas de ellas muy vinculadas con diferentes sectores de activación política, incluso de la lucha armada) y aquellas que nucleaban a militantes, intelectuales, artistas y referentes. Si entre las primeras ejemplifica con AGA (Asociación Gremial de Abogados) de Capital Federal, en las segundas focaliza la COFAPPEG y ubica en el tercer grupo al Foro por los Derechos Humanos. Para el caso especial de Córdoba interesa su genealogía de COFAPPEG (aunque se concentra luego en el caso de Capital Federal): "claro ejemplo de un núcleo de familiares de detenidos, con fuertes vínculos con organizaciones revolucionarias" (Eidelman, 2010, p. 346). La identifica con la acción frentista del PRT- ERP, marca su inicio a comienzos de 1970, en coincidencia con el aumento de las detenciones de militantes de esa organización, y sitúa la conformación inicial de estas agrupaciones fuera de Buenos Aires, en ciudades del interior, entre las que menciona a Córdoba. Vincula su involucramiento en la defensa de los presos políticos por el efecto creciente de la represión sobre sus militantes y combatientes, con datos de la cantidad de muertos y detenidos por años, destacando que, en acuerdo con Pozzi (2001), a comienzos de 1973 un tercio del partido estaba detenido. Dentro de esas caídas, se menciona el lugar destacado de Córdoba por cuantía y porque parte de la dirección fue detenida en la ciudad capital en agosto de 1971 (Eidelman, 2010, p. 350). Un aporte igualmente central es la referencia a un Informe realizado desde Córdoba hacia 1972 que incluye más de 60 casos de denuncia de la situación de las y los presos políticos, asesinatos y torturas. ${ }^{23}$ Según el autor, el folleto incluía también una declaración de principios de la organización:

“COFAPPEG está constituida exclusivamente por familiares de presos políticos, estudiantiles y gremiales, es autónomo o sea que no depende de ninguna otra entidad o agrupación, se maneja con sus propios fondos y su finalidad primordial es el apoyo a todos los presos sociales y familiares dependientes sin interesar a que grupo per-

23 “El trabajo de unas 50 páginas estaba básicamente integrado por testimonios, desde el año 1970, de hombres y mujeres detenidos en Córdoba, Rosario, Tucumán, La Plata, Mendoza, Buenos Aires, Santiago del Estero, Corrientes y Capital Federal" (Eidelman, 2010, p. 369).

Anuario de la Escuela de Historia Virtual - Año 10 - N 16 - 2019: pp. 71-92. ISSN: 1853-7049 
tenecen, toda vez que entendemos que todos y cada uno lucha contra "el enemigo común" Por la libertad de todos los presos. ¡Viva la patria!".24

Desde el análisis de la represión, Eidelman llega a reconocer en estas agrupaciones además un antecedente del $\mathrm{MDH}$, tal como quienes nos ocupamos de la historia de la militancia en la Argentina reciente arribamos a la misma conclusión. En efecto, una de las especificidades que, a mi juicio, tiene la Historia Reciente Argentina es que es un trabajo territorialmente más extendido el que permite construir explicaciones más complejas de los procesos que se están estudiando. Así lo han demostrado un conjunto de investigaciones sobre el movimiento de derechos humanos en Argentina al ejemplificar densamente los avances producidos con esta perspectiva, que se juega en diferentes escalas, articulando lo local, regional, nacional, trasnacional. Por ello, y considerando esa acumulación de investigaciones previas y otras en curso, voy a detenerme en los antecedentes más recientes sobre la historia del MDH que incluyen a las comisiones. ${ }^{25}$

En el caso de Rosario, tomo las contribuciones de Marianela Scocco (2018), relativas a la conformación del movimiento de derechos humanos y una reciente ponencia (Scocco, 2019), que aborda con profundidad la defensa de presos políticos entre 1971 y 1975. Scocco adelanta la conformación de antecedentes de su objeto a 1955, incluyendo el período de la "revolución argentina" dentro de estos largos antecedentes entre represión y respuestas sociales. Analiza como antecedentes de la acción defensista al periodo circunscripto entre 1968 y 1975, subperiodizando la etapa dictatorial y el retorno peronista. En la primera, aborda la conformación de los núcleos defensistas en la tradición de agrupaciones de larga data como la LADH y de los abogados defensistas, junto a la más reciente politización de agrupaciones de abogados (con la constitución de la AAR), la acción de la opositora CGTA en Rosario y la solidaridad desplegada por el MSTM. En su minuciosa reconstrucción, la historiadora logra articular esas diferentes vertientes de actuación con las modificaciones operadas en la represión, analizando casos testigos, de fuerte impacto para Rosario. Reconstruye el arco de las organizaciones de defensa de presos políticos que tuvo expresión en dicha ciudad, mostrando varias similitudes con el planteo de Eidelman y con el nuestro. En efecto, demuestra que hubo varios nucleamientos, algunos con pertenencia e identidad política expresamente reconocida. También pondera la actuación de familiares directos y allegados a las víctimas de la represión en dichas organizaciones, así como los vínculos de estas con organizaciones o redes nacionales. Al igual que en Córdoba, identifica el accionar de OSPPEG y COFAPPEG, y si bien se habrían ido produciendo diferenciaciones entre aquellos que defendían a militantes peronistas y otros a las izquierdas, armadas y no armadas, también releva a partir de testimonios que Rosario habría mantenido cierta tendencia a no separarse como en otras regionales del país. Claramente, los trabajos de Eidelman (2010), Scocco (2018), Chama (2016), pero también los de Alonso (2011) en Santa Fe, y los nuestros para Córdoba (Oviedo y Solis, 2006; 2007; Solis, 2014) muestran esa pluralidad y dinamismo de las denominadas comisiones en defensa de los presos políticos durante la dictadura anterior, exponiendo la relevancia que las militancias y la activación alcanzaron en esas localizaciones, así como la generación de diferentes respuestas sociales ante el avance represivo.

24 “Torturas en Argentina”, COFAPPEG, Córdoba, agosto 1972, citado en Eidelman (2010, p. 369).

${ }^{25}$ Las investigaciones han sido producidas en Santa Fe, Rosario, Tucumán, Neuquén, Mar del Plata y Córdoba. Ver resultados colectivos en Kotler (2014) y actualizaciones en Alonso (2018).

Anuario de la Escuela de Historia Virtual - Año 10 - N 16 - 2019: pp. 71-92. ISSN: 1853-7049 
En resumen, lo anterior expone los aportes de los trabajos situados en la historia de la represión y de las militancias, contando con contribuciones ancladas en Buenos Aires y en otras ciudades del interior del país; unas y otras destacan la similitud de algunos procesos, aunque también los rasgos propios, y refieren igualmente al lugar central de la experiencia de Córdoba, sobre todo desde el acontecimiento "Cordobazo". Pero, ¿qué avances se efectuaron sobre esta red de conflicto que correlaciona violencia represiva y respuestas sociales para Córdoba específicamente?

\section{Los nuevos aportes sobre Córdoba}

Existen nuevas obras sobre el período en Córdoba; algunas más contextuales y otras dedicadas a actores o procesos específicos. Desde la nueva historia política, para César Tcach (2012), el período iniciado tras el golpe de estado de 1966 en la provincia marca la etapa del gobierno de "las familias" políticas hasta el Cordobazo. Allí, entiende que hubo participación militar y civil en los principales cargos, junto a fusiones ideológico- discursivas entre la tradición del integrismo católico y la doctrina contrarrevolucionaria. Pero, además, constata que más allá de esas familias tradicionales, hubo un apoyo pleno del bloque social dominante al gobierno, relevando apoyos de empresarios del comercio y la industria local, incluso de empresas extranjeras y, por supuesto, de jerarquía de la iglesia católica. Así, el viejo patriciado fundía sus alianzas con el capital nacional y trasnacional, contra el populismo, el marxismo y el pluripartidismo, señala el autor. Luego de analizar cómo se fueron conformando núcleos de acción de oposición al régimen, y de valorar la incidencia del Cordobazo como episodio político para el devenir del Onganiato, realiza un aporte sustancial para comprender la dinámica represiva local. En su epílogo, Tcach (2012, p. 230) refiere que "hacia 1969 ya funcionaba en Córdoba una Comunidad de Inteligencia", de actividad secreta, que reunía a las autoridades provinciales, rectores de las dos universidades (católica y nacional), al jefe de policía, militares del Comando del III Cuerpo de Ejército y de la Fuerza Aérea. Se trataba pues de un organismo de carácter asesor al gobierno provincial -y eventualmente nacional- para la toma de decisiones; organismo éste que tendrá actuaciones destacadas en una dictadura posterior.

Por su parte, Emilse Pons (2010) señala para el escenario poscordobazo, los dilemas y significados del mismo atribuidos por diferentes actores en las lecturas de la coyuntura. Un elemento interesante es que identifica como recurrencia en los discursos oficiales atribuir los hechos de violencia del Cordobazo a "la subversión, otorgándole a los mismos un carácter planificado y organizado [...] del comunismo, en su versión marxista leninista" y negando cualquier acción espontánea (Pons, 2010, p. 332). Advierte que sólo el gobernador Caballero identificaba ciertas demandas (descontentos menores) como causales, pero que entendía al Cordobazo "como una huelga, que terminó en guerrilla" (citado en: Pons, 2010, p. 333). Esa línea de culpabilización a la subversión, además como un fenómeno foráneo que no tenía causas en el país -y que fue confirmada por el documento de la Comisión Nacional de Seguridad, CONASE, a poco de producirse la revuelta, será mantenida hasta 1971 cuando comience a reconocerse que la subversión es también un problema local y "no solo algo que viene del exterior" (Pons, 2010, p. 334). Otro interventor, el gobernador Bas lo interpretará como un problema delictual y policial, hasta que se produzca el Viborazo bajo la intervención de Uriburu, para quien la subversión constituía el principal problema -en particular, por su ligazón con la acción 
gremial, apoyando por ese motivo la represión al conflicto social y la protesta (Pons, 2010, pp. 348 y ss.). Tras los eventos del Viborazo, Pons (2010, p. 352) señala que la intervención posterior a cargo de Guozden reafirmó la vía represiva, combinando acciones legales e ilegales, especialmente direccionadas hacia los sectores sindicales que no habían sido cooptados y la guerrilla; un aumento de la represión que fue denunciado por organizaciones como LADH y "OSPEG" [sic]. Entonces, más allá del componente civil o militar de las intervenciones, hay un giro hacia la identificación del conflicto como cuestión subversiva a la que cabe la acción represiva del estado. Existe también un trabajo más general y breve de María Carla Bertotti (2009) sobre el Cordobazo y su escenario posterior que -a mi criterio- sólo agrega algunos datos de entrevistas anónimas relativos a los medios de comunicación, donde se afirma, por ejemplo, que la identificación y detención de los militantes se habría facilitado por el secuestro de las cintas de los canales televisivos locales que cubrieron el acontecimiento (Bertotti, 2009, p. 341), pero no hay mención alguna a las formas de resistir la violencia represiva.

Ahora bien, concentrándonos en aportes recientes de la historia de las militancias, vamos a referir dos contribuciones. La tesis doctoral de Laura Ortiz (2015), enfocada principalmente en el clasismo y, por lo tanto, en los avatares del movimiento obrero entre la violencia y la represión, presenta una caracterización de los cambios en la represión entre 1969 y 1972 en Córdoba. Como rasgo central arguye que tendió a ser "más selectiva hacia adentro del activismo obrero" (Ortiz, 2015, p. 62). Ello implicó mayor cantidad de detenidos en los paros activos, tiempos de prisión más largos, aumento de la cantidad de presos políticos particularmente de los que estaban a disposición de PEN por la declaración del Estado de Sitio desde el 30/06/1969 según la Ley №18262. Esa selectividad mayor la advierte también en los blancos represivos. En su opinión, los incitadores o culpables de acciones subversivas se identificaron cada vez más con los sectores "clasistas y combativos", desde 1971, y menos con los sectores ortodoxos, de la burocracia o de otras identidades políticas menos radicalizadas (Ortiz, 2015, p. 63). Y menciona las estrategias usadas: por ejemplo, los consejos de guerra para los protagonistas del Cordobazo -luego amnistiados hacia fines de 1969- que fueron aplicados a dirigentes de renombre y de variadas corrientes dentro del sindicalismo, pero también el aumento de la presencia policial en las protestas, el reforzamiento con fuerzas armadas y de seguridad nacionales, la connivencia empresa/estado para la represión y de la justica que no investigaba las denuncias. Sobre el interés más directo de este artículo, menciona las redes y organizaciones de denuncia a nivel nacional que inscribían el avance represivo, recogiendo dos noticias, una del Encuentro Nacional de los Argentinos en noviembre de 1969 y otra de la Comisión Nacional de solidaridad con los presos políticos en diciembre del mismo año (Ortiz, 2015, p. 63).

En los trabajos de Leandro Inchauspe sobre las organizaciones armadas en Córdoba, en especial del PRT-ERP, hay avances respecto a la discursividad de la violencia y el cambio de sus significados para las clases dominantes. En su análisis sobre la lógica de la guerra interna entre 1966 y 1970 (Inchauspe, 2010), el autor identifica cómo desde la asunción de las autoridades tras el golpe de 1966, hay una recurrente discursividad antisubversiva y anticomunista, de fuerte carácter performativo, que va creando al enemigo antes de la existencia de las organizaciones armadas en la provincia, siguiendo una postulación de César Tcach en ese sentido. ${ }^{26}$ Discursos encendidos, filiados en la

${ }^{26}$ Citado por: Inchauspe, 2010, p. 356.

Anuario de la Escuela de Historia Virtual - Año 10 - Nº 16 - 2019: pp. 71-92. ISSN: 1853-7049 
doctrina de seguridad nacional, con componentes cristianos y moralizadores de la vida privada, junto a operativos espectacularizados que buscaban generar consenso al agigantar la amenaza. Igualmente, aporta sobre la gimnasia represiva de las protestas, por ejemplo, en las protagonizadas por sectores estudiantiles donde, junto a situaciones inéditas, como la muerte de Pampillón, se tornaron recurrentes los gases, detenciones y enfrentamientos entre manifestantes y la policía que llegaron a convertirse en batallas campales (Inchauspe, 2010, p. 375). En otra contribución, el autor se aboca a la discursividad legitimadora de la violencia por parte de dirigentes políticos locales, entre 1970 y 1972 contexto de emergencia y acción en Córdoba del ERP, postulando "que una importante parte de la dirigencia partidaria participaba de la aceptación social de la violencia política, ya sea justificándola como respuesta a la violencia de la dictadura militar, o bien considerándola como inherente a la época o, en menor medida, porque compartían los objetivos revolucionarios que la guiaban". De igual modo, analiza expresiones de rechazo, en diversos tonos (Inchauspe, 2007, p. 4). Ello implicaría ir precisando diferentes posicionamientos respecto a un cierto tipo de violencia, más asociada a las protestas de Córdoba y a su escenario posterior, de las evaluaciones sobre las acciones locales de las organizaciones armadas, mostrando que no hubo simplemente un proceso de rechazo ascendente, sino también diversos usos de aceptación y rechazo en ambos. En lo específico, con sus trabajos sobre la conformación del PRT-ERP en Córdoba incluida en la emergencia de las organizaciones armadas en el espacio local, Inchauspe (2006) ha reconstruido dichas tramas destacando además su gran visibilización en la prensa cordobesa, abonando la idea de que algunas de estas organizaciones de solidaridad estaban directamente vinculadas con la represión a esas militancias.

Por otra parte, respecto a la actuación de los abogados en esta ciudad mediterránea, los trabajos de Rafael Ortiz $(2007 ; 2011)$ han avanzado en esa línea, reconstruyendo el compromiso de los letrados, distinguiendo cuáles fueron sus principales organizaciones, tipos de acción desarrollada e incluso el impacto de la represión, hasta convertirlos de solidarios con la causa en represaliados muy tempranamente.

\section{Las políticas estatales de memoria}

Uno de los avances significativos que aportaron las políticas públicas de la memoria en los años de los denominados gobiernos kirchneristas entre 2003 y 2015, fue la producción y difusión de informes que cuantifican e identifican las víctimas del accionar represivo. Para el período que nos ocupa, la fase de intensificación represiva en torno al Cordobazo y el ciclo de protesta que le sucedió, contamos con datos integrados en el Registro Unificado de Víctimas del Terrorismo de Estado producido por la Secretaría de Derechos Humanos de la Nación (en adelante RUVTE). ${ }^{27}$ En dicho registro se incorpora el Anexo 1 que corresponde al "Listado de víctimas del accionar represivo ilegal del Estado argentino. Víctimas de desaparición forzada y asesinato en hechos ocurridos entre 1966 y 1983"; un listado de 8631 casos ordenados alfabéticamente.

Aquí valen dos aclaraciones. En primer lugar, que el registro periodiza a las víctimas producidas por y entre dos dictaduras, es decir, unificando las experiencias dictatoriales iniciadas en 1966 y 1976, por un lado, y considerando igualmente el período del inter-

\footnotetext{
${ }^{27}$ La versión consultada es la que estuvo disponible hasta el final del gobierno de C. Fernández de Kirchner en la página de la SDH Nación. Consta de dos tomos, ordenados alfabéticamente.
}

Anuario de la Escuela de Historia Virtual - Año 10 - Nº 16 - 2019: pp. 71-92. ISSN: 1853-7049 
regno constitucional entre ambas, organizando la información de los blancos represivos desde que, podríamos conjeturar, la escena de la militarización de la seguridad se conjugó con la efectiva tendencia a la intervención directa de las fuerzas armadas. En sus propias palabras:

"Este criterio se funda en los sucesivos asertos jurídicos y de investigación que ya desde el comienzo de la etapa democrática fueron verificando una suerte de continuidad entre la denominada Doctrina de Seguridad Nacional de 1966, y su aplicación práctica: el terrorismo de Estado de 1976, en la medida que la evidencia advierte sobre la articulación progresiva del accionar represivo ilegal entre distintos actores institucionales, estatales y paraestatales, policiales y militares en el período intermedio, que encuentra su expresión acabada y final en la instauración plena del plan de exterminio de opositores políticos por parte de la última dictadura cívico-militar". ${ }^{28}$

La incorporación de la dimensión represiva del estado en ambas dictaduras y el interregno intermedio sintoniza con los avances producidos desde la academia que ya mencionamos. Por las características del Registro, la información que aporta no es sobre las respuestas sociales y la organización de la solidaridad, sino sobre el universo de las víctimas que el estado reconoce y las responsabilidades institucionales, en el caso en que han sido determinadas, de las diferentes agencias represivas, sean éstas mediante acciones públicas o clandestinas, como productoras de las mismas bajo el concepto de terrorismo de estado. Es preciso aclarar que el registro sólo contiene víctimas de desaparición forzada y de asesinatos. Sin embargo, en las fichas individuales, es posible identificar acciones represivas previas, cuando se incorpora en cada caso si hubo situaciones anteriores de detención.

¿Qué contribuciones hace sobre Córdoba? Una primera lectura de la información contenida fue procesada determinando las y los represaliados según años del registro que se dieron en Córdoba. De la misma surge que en 1966, 1967 y 1968 no hay víctimas identificadas en Córdoba. Esto llama la atención porque hubo al menos una muerte producida por la represión al conflicto en septiembre de 1966 que fue paradigmática para los propios sectores activados entonces. Me refiero al asesinato de Santiago Pampillón, militante estudiantil muerto por las heridas recibidas por la policía en una movilización estudiantil en plena zona céntrica, a la altura de la galería Cinerama. La figura de Pampillón muy pronto adquirió carácter de símbolo para la activación popular.

En 1969 el registro incluye cuatro asesinatos producidos por la represión en el Cordobazo. Dichas muertes son calificadas como “Asesinato Represión ilegal en reunión pública o manifestación político-gremial", es decir como consecuencia de la acción represiva estatal, aunque no determina qué fuerza fue la responsable. En la memoria popular, de los mismos sólo resulta conocido Máximo Mena (RUVTE, p.794), el obrero asesinado al inicio de la llegada de la movilización hacia el centro y, según los trabajos clásicos, cuya muerte resultaría un disparador de la violencia colectiva de esas jornadas. El lugar de su caída, la intersección de Arturo M. Bas y Bv. San Juan, se ha convertido, por años, en sede de actos conmemorativos del Cordobazo.

Junto a él se incluye a dos jóvenes varones de 18 años y una mujer de 49 años. Se trata de Daniel Octavio Castellano, Leonardo Gulle y Velia Noemí Guerra (RUVTE, pp. 276,

${ }^{28}$ Registro Unificado de Víctimas del Terrorismo de Estado, Anexo 1, p. 4.

Anuario de la Escuela de Historia Virtual - Año 10 - Nº 16 - 2019: pp. 71-92. ISSN: 1853-7049 
$592,596)$. El primero fue herido en horas del mediodía del 29 de mayo, en el centro, y falleció en una clínica al día siguiente; era oriundo de Villa Dolores. Los dos restantes fueron asesinados producto de la represión en los barrios de la ciudad. La mujer, en barrio Yofre, al este de la ciudad capital; el 30 de mayo fue herida y luego fallece, sin especificar dónde o cuándo. El varón fue asesinado en barrio Residencial América, calles Puerto de Palos y La Habana, en horas de la tarde y muy cerca de la Sociedad Belgrano, un club de sociabilidad popular reconocido. ${ }^{29}$ Estas son las únicas víctimas asesinadas que se incluyen, no hay datos de desaparecidos ni de detenidos.

Luego del Cordobazo, el rasgo más significativo del registro es el direccionamiento de las muertes hacia los militantes de las organizaciones armadas, en coincidencia con la apertura de su fase de mayor accionar, visibilidad y capacidad organizativa y operativa. Un análisis del registro por año muestra que en 1970 no hay asesinados ni desaparecidos en Córdoba incorporados, pero sí mención a quienes luego serán víctimas y en ese año fueron detenidos. De este modo, el registro permite seguir las trayectorias como represaliados de quienes tuvieron detenciones antes de sus respectivos secuestros o asesinatos, aunque no figuran todos los casos que conocemos o al menos se han mencionado en otros apartados. En diciembre de 1970 fueron detenidos militantes de las FAR luego de una acción contra un banco en la ciudad capital. Marcos Osatinsky, Carlos Heriberto Astudillo, Alberto Miguel Camps y Alfredo Elías Kohon fueron detenidos en Bajo Palermo. El primero fue asesinado en 1975 y los otros tres fueron víctimas de la masacre de Trelew, sólo Camps logró sobrevivir herido, pero fue asesinado en 1977 en Buenos Aires.

En 1971 se registraron nuevas detenciones muy simbólicas de combatientes, quienes luego fueron asesinados en diferentes episodios represivos en años siguientes y también asesinatos de militantes comprometidos con la lucha armada. Dentro de las primeras, me refiero a las detenciones de, por ejemplo, Mariano Pujadas, ${ }^{30}$ detenido en Córdoba en junio y quien será asesinado en la masacre de Trelew. En agosto, los militantes de PRTERP Mario Roberto Santucho, Humberto Toschi y Alejandro Jorge Ulla son detenidos en una casa de barrio General Bustos; en noviembre, María Antonia Berger, de la FAR también fue detenida y será herida en Trelew al año siguiente. Junto a ellos y dentro del segundo grupo, se producen igualmente asesinatos simbólicos: los tres primeros muertos del PRT-ERP, asesinados en un operativo en barrio San Martín; Juan de Valle Taborda, José Alberto Polti y Marcelo Manuel Lescano, cuya muerte se convirtió en un hecho de fuerza simbólica para la militancia perretiana. Hubo además otras muertes producidas en el interior provincial: el asesinato de otro militante llamado a convertirse en ícono para la lucha armada, José Antonio Navarro ${ }^{31}$, hecho producido en julio en una

\footnotetext{
${ }^{29}$ A sólo una cuadra de la intersección de Diagonal Ica y Av. Alem, en la zona noreste.

${ }^{30}$ En 1968 integra la Agrupación de Estudios Sociales de Córdoba (AES) conformada en la UCA. En la semblanza de Baschetti, el Cordobazo resultó clave en su politización: “Desde el Cordobazo hasta la fría mañana del 22 de agosto de 1972 en Trelew, con años de militancia intensamente vividos, se concreta la transformación de nuestro Mariano en el "Gaita", como lo llamaban cariñosamente sus compañeros. Ya era Peronista. Ya era Revolucionario. Ya era Montonero. Prófugo después de la toma de La Calera, es detenido el 22 de junio del '71 en Córdoba y trasladado a Rawson (Chubut), formando parte del primer grupo de prisioneros políticos enviados en condiciones calamitosas al inhóspito y gélido sur de nuestro país." URL: http://www.robertobaschetti.com/biografia/p/202.html (Descarga 16/03/2019).

${ }^{31}$ Según la reconstrucción biográfica de Roberto Baschetti: “En agosto de 1968 participa del 1ํㅡㄹ Congreso del Peronismo Revolucionario y en enero del año siguiente, concurre al plenario peronista de Pajas Blancas, Córdoba. Está entre los fundadores de la organización Montoneros y será su jefe luego de la muerte de Abal Medina y Ramus (Septiembre de 1970. Pizzería “La Rueda”)". Fue enviado a Córdoba donde quedó como
} 
zona rural de la serranía, entre Villa Ciudad de América y el paraje Los Quebrachos. En la misma persecución, otro militante, Juan Alberto Díaz, resultó muerto cerca de Berrotarán. En 1972, el único caso de asesinato durante un allanamiento incluido es el de un militante montonero, Raúl Aristóbulo Bracco, ocurrido en barrio Alto Alberdi. ${ }^{32}$

Una mirada de conjunto permite colegir de ese registro, realizado por las políticas estatales de la memoria, que progresivamente las muertes producidas por el estado comenzaron, en Córdoba, a incluir de aquellas ocurridas en ocasión de la protesta urbana a las acciones contra los militantes de las organizaciones armadas. Ello muestra las ampliaciones del universo de represaliados y confirma la relevancia que tuvo Córdoba, en el ciclo de protesta, para las organizaciones político militares, justamente en su fase de expansión.

\section{A modo de balance y conclusión}

De modo breve y haciendo un ejercicio de balance provisorio, desde nuestras primeras escrituras, que aún tenían un sesgo conjetural, sobre las organizaciones de solidaridad contra la represión en el poscordobazo, se han producido contribuciones significativas provenientes del fecundo campo de la historia reciente y en particular del renovado interés de las y los historiadores y cientistas sociales sobre el período, con nuevas preguntas y miradas, pero también recortando nuevas localizaciones. A ello se ha incorporado lo producido por el acierto de las políticas estatales que, junto con el procesamiento institucional de las demandas de verdad, justicia y memoria, han sistematizado y visibilizado la acción represiva del estado y reconstruido el universo de los represaliados con una mirada que contiene y excede a la última dictadura cívico militar. Asimismo, y aún desde abordajes y preocupaciones heterogéneas dentro de la historiografía local, también se han producido aportes que contextualizan y entraman aquellas primeras contribuciones sobre la existencia de las organizaciones antecesoras del MDH en Córdoba. Igualmente, hay puntos en debate, por ejemplo, cuánto de continuidad existió entre estas formas de organizar la solidaridad frente a la acción represiva y las formas que se alumbrarán bajo nuevas modalidades de la violencia estatal. Allí, me inclino por pensar que parte del debate consiste en definir en qué buscamos la continuidad, si es en las biografías, algo que en Córdoba sí ocurrió y en otros lugares aparentemente no, o más integralmente en los modos de responder socialmente y construir causas públicas.

Otro punto de debate es cómo se fueron configurando respuestas diferenciadas según la incidencia de los cambios en las modalidades represivas y su imbricación con el universo cambiante de los represaliados. Allí, también tiendo a pensar que se precisa incorporar otra dimensión y es la propia interacción política de los grupos activados que tuvieron posiciones diferenciadas dentro de una coyuntura que fue virando de la impugnación al régimen hacia la salida electoral. Al menos para Córdoba esto sigue teniendo importancia explicativa. Otro debate es el planteado respecto al lugar de Córdoba en este

responsable de la Regional y finalmente muere tras ser herido en una persecución policial por un hecho armado en el sur provincial. Fue enterrado en el Cementerio San Vicente, "como N.N." Rescatado y llevado a Buenos Aires por Montoneros en 1974. URL: http://www.robertobaschetti.com/biografia/n/10.html (Descarga 16/03/2019).

${ }^{32}$ Fue militante montonero. Lo matan en Córdoba, durante un allanamiento. Ocurrió el 31 de mayo de 1972 cuando las fuerzas represivas asaltaron la casa sita en Achával Rodríguez 2054, del Barrio Alto Alberdi. URL: http://www.robertobaschetti.com/biografia/b/211.html (Descarga 16/03/2019).

Anuario de la Escuela de Historia Virtual - Año 10 - Nº 16 - 2019: pp. 71-92. ISSN: 1853-7049 
proceso. Considero que -tanto por el acontecimiento Cordobazo y su incidencia en el escenario posterior, como porque cuando la lucha armada se expresó con mayor potencia desde 1970 aquí se instalaron las direcciones nacionales de las organizaciones- Córdoba sigue siendo, entonces, un lugar fundamental para pensar las respuestas sociales a la represión, incluso para sopesar las transformaciones de esa centralidad y sus derivas en un tiempo muy corto, pero igualmente intenso. Por último, merece destacarse la importancia de poner en diálogo la producción académica y las políticas de memoria, siendo necesario avanzar en esa línea, por ejemplo, cotejando otras actualizaciones disponibles de la reconstrucción del universo de represaliados. En este sentido, estimamos, lo anterior ha querido mostrar un modo de pensar el desafío de hacer dialogar saberes, temporalidades, agencias e instituciones; diálogos que la historia reciente argentina promueve y potencia.

\section{Referencias bibliográficas}

Alonso, L. (2018). Las luchas pro derechos humanos. Logros y perspectivas de sus estudios. En G. Águila, L. Luciani, L. Seminara y C. Viano, C. (Comps.). La historia reciente en Argentina. Balances de una historiografía pionera en América Latina. (pp. 109-128). Buenos Aires: Imago Mundi.

Bertotti, M. C. (2009). Del Cordobazo al Golpe de Estado del '76. Una aproximación a las confrontaciones sociales en la provincia de Córdoba. En I. Izaguirre, et al. Lucha de clases, guerra civil y genocidio en la Argentina. 1973-1983 (pp. 337-351). Buenos Aires: Eudeba.

Celentano, A. (2014). Maoísmo y nueva izquierda. La construcción de Vanguardia Comunista (1965-1969). En M. C. Tortti (Dir.); M. Chama y A. Celenteno (Co-dir.), La nueva izquierda argentina (1955-1976). Socialismo, peronismo y revolución (pp. 83-109). Rosario: Prometeo.

Chama, M. (2000). Compromiso político y práctica profesional a principios de los setenta: El caso de Asociación Gremial de Abogados. Sociohistórica, 7, 81-107.

Chama, M. (2007). Movilización y politización: los abogados de Buenos Aires, 1968-1973. En A. Pérotin-Dumon (Ed.). Historizar el pasado vivo en América Latina. URL: http://www.historizarelpasadovivo.cl/downloads/chama.pdf (Descarga 21/04/2019).

Chama, M. (2016). Movilización y activismo por la defensa de los presos políticos durante los primeros setenta en Argentina: actores, tramas y estrategias. Ponencia presentada en IX Jornadas de Sociología de la UNLP. Universidad Nacional de La Plata: Ensenada. URL: http://www.memoria.fahce.unlp.edu.ar/trab_eventos/ev.8871/ev.8871.pdf. (Descarga 21/04/2019).

D’Antonio, D. (2016). La prisión política en los años setenta. Historia, género y política. Buenos Aires: Biblos.

Duhalde, E. L. (1999). El Estado Terrorista Argentino. Quince años después, una mirada crítica. Buenos Aires: Eudeba.

Eidelman, A. (2010). El desarrollo de los aparatos represivos del Estado argentino durante la "Revolución Argentina", 1966-1973. (Tesis de Doctorado). Universidad de Buenos Aires: CABA.

Flores, G. (2004). SITRAC-SITRAM. La lucha del Clasismo contra la burocracia sindical. Córdoba: Editorial Espartaco. 
Franco, M. e Iglesias, M. (2015). El estado de excepción a escala comparada. Notas a partir de los casos argentino, chileno y uruguayo durante la década de 1950. Quinto Sol, $19(1), 1-23$.

Gordillo, M. (1999). Movimientos sociales e identidades colectivas: repensando el ciclo de protesta obrera cordobés de 1969-1971. Desarrollo Económico, 39 (155), 385-408.

Gordillo M. (2001a). La lucha debe continuar. Los trabajadores peronistas de Córdoba y sus definiciones identitarias. En M. Gordillo (Ed.), Actores, prácticas, discursos en la Córdoba combativa. Una aproximación a la cultura política de los '70 (pp. 49-70). Córdoba: Ferreyra Editor.

Gordillo, M. (2001b). Introducción. En M. Gordillo (Ed.), Actores, prácticas, discursos en la Córdoba combativa. Una aproximación a la cultura política de los '70 (pp. 11-26). Córdoba: Ferreyra Editor.

Gordillo, M. (2001c). El contexto: las condiciones para el surgimiento de un movimiento social y político. En M. Gordillo (Ed.), Actores, prácticas, discursos en la Córdoba combativa. Una aproximación a la cultura política de los '70 (pp. 29-46). Córdoba: Ferreyra Editor.

Inchauspe, L. (2006). La guerra revolucionaria ha comenzado. La aparición pública del PRT-ERP en el escenario cordobés post Cordobazo (1970-1971). Ponencia presentada en I Jornadas de Historiografía Regional. UNNE, Resistencia.

Inchauspe, L. (2007). No justifico la violencia, pero... La dirigencia política cordobesa y la lucha armada, Córdoba 1970-1972. Colección Voces y Argumentos (13), Centro de Estudios Avanzados: Universidad Nacional de Córdoba.

Inchauspe, L. (2010). La lógica de la guerra interna en las primeras etapas de la Revolución Argentina (1966-1970). En C. Tcach (Coord.). Córdoba Bicentenaria. Claves de su historia contemporánea (pp. 355-388). Córdoba: Editorial de la Universidad Nacional de Córdoba.

Iturralde. M. y Solis, A. C. (2015). Derechos humanos y democratización: una mirada desde Córdoba y Mar del Plata. En M. Ferrari y M. Gordillo (Comps.). La reconstrucción democrática en clave provincial (pp. 227-256). Rosario: Prohistoria.

Kotler, R. (Coord.) (2014). En el país del sí me acuerdo. Los orígenes nacionales y transnacionales del movimiento de derechos humanos en Argentina: de la dictadura a la transición. Buenos Aires: Imago Mundi y Red Latinoamericana de Historia Oral.

Ortiz, E. R. (2007). Los Abogados del Pueblo. El derecho contra el poder. Córdoba: Narvaja Editor.

Ortiz, E. R. (2011). Los abogados y la lucha por el derecho. Estudios (25), 233-247.

Ortiz, M. L. (2015). Violencia y represión. Los trabajadores clasistas en Córdoba, 1969-1976. Tesis Doctoral. Universidad de Buenos Aires: mimeo.

Oviedo, S. y Solis, A. C. (2007). La génesis de los organismos de derechos humanos en Córdoba. LA BASTILLA. Revista de Historia y política, 1 (0), 99-123.

Oviedo, S. y Solis, A. C. (2006). Violencia institucionalizada y formas de resistencia social: los organismos de Derechos Humanos en Córdoba durante la dictadura. (Trabajo Final de Licenciatura en Historia). Universidad Nacional de Córdoba: Córdoba.

Pons, E. (2010). El fracaso del proyecto autoritario en Córdoba y la eclosión de la movilización popular (1966-1973). En C. Tcach (Coord.), Córdoba Bicentenaria. Claves de su historia contemporánea (pp. 297-354). Córdoba: Universidad Nacional de Córdoba. 
92 I Organizar la solidaridad contra la represión en Córdoba...

Pontoriero, E. (2015). Estado de excepción y contrainsurgencia: el Plan CONINTES y la militarización de la seguridad interna (1958-1962). Contenciosa 3 (4), s/n.

Pozzi, P. (2001). Por las sendas argentinas... El PRT-ERP. La guerrilla marxista. Buenos Aires: Eudeba.

Scocco, M. (2018). La conformación del movimiento de derechos humanos de Rosario. Experiencias, conflictos y relaciones desde una perspectiva histórico-regional (1970-1985). (Tesis de Doctorado). Universidad Nacional de Rosario: Rosario.

Scocco, M. (2019). La Comisión de Familiares de Presos Políticos, Estudiantiles y Gremiales (CoFaPPEG). Defensa, solidaridad y apoyo a los presos políticos (1971-1976). Ponencia presentada en XVII Jornadas Interescuelas/Departamentos de Historia Catamarca. Universidad Nacional de Catamarca: San Fernando del Valle de Catamarca.

Scott, J. (2004 [2000]). Los dominados y el arte de la resistencia. Discursos ocultos. México: Ediciones Era.

Servetto, A. (1998). De la Córdoba combativa a la Córdoba militarizada, 1973-1976. Córdoba: Ferreyra Editor

Solis, A. C. (2014). De las comisiones a los organismos en Córdoba: derechos humanos, dictadura y democratización. En R. Kotler (Coord.) En el país del sí me acuerdo. Los orígenes nacionales y transnacionales del movimiento de derechos humanos en Argentina: de la dictadura a la transición (pp. 129-156). Buenos Aires: Imago Mundi y Red Latinoamericana de Historia Oral.

Soto, A. (2004) Vidas y luchas de VC. Tomo 1 (6). La lucha contra la represión. Disponible en Web del Partido de la Liberación. URL: http://partidoliberacion.org/2019/01/6-lalucha-contra-la-represion/ [Descarga 19/12/2019].

Tcach, C. (2012). De la Revolución Libertadora al Cordobazo. Buenos Aires: Siglo XXI Editores.

Veiga, R. (1985). Las organizaciones de derechos humanos. Buenos Aires: CEAL.

Para citar este artículo:

Solis, Ana Carol (2019). Organizar la solidaridad contra la represión en Córdoba. Revisiones desde la historia reciente y las políticas de memoria. Anuario de la Escuela de Historia Virtual, 16, 71-92. 